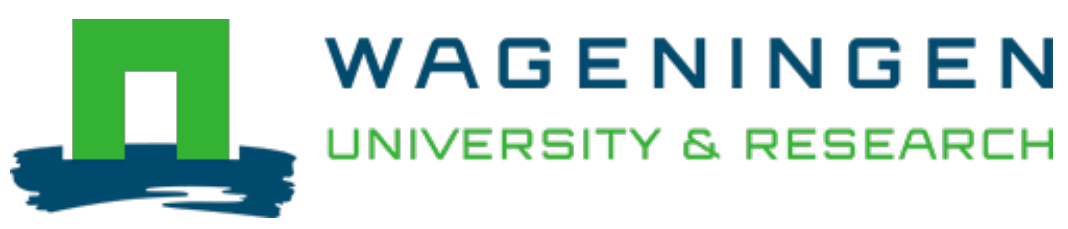

\title{
Prediction of spoilage of tropical shrimp (Penaeus notialis) under dynamic temperature regimes
}

\author{
International Journal of Food Microbiology \\ Dabade, D.S.; Azokpota, P.; Nout, M.J.R.; Hounhouigan, D.J.; Zwietering, M.H. et al \\ https://doi.org/10.1016/j.ijfoodmicro.2015.06.010
}

This publication is made publicly available in the institutional repository of Wageningen University and Research, under the terms of article $25 \mathrm{fa}$ of the Dutch Copyright Act, also known as the Amendment Taverne. This has been done with explicit consent by the author.

Article 25 fa states that the author of a short scientific work funded either wholly or partially by Dutch public funds is entitled to make that work publicly available for no consideration following a reasonable period of time after the work was first published, provided that clear reference is made to the source of the first publication of the work.

This publication is distributed under The Association of Universities in the Netherlands (VSNU) 'Article $25 \mathrm{fa}$ implementation' project. In this project research outputs of researchers employed by Dutch Universities that comply with the legal requirements of Article $25 \mathrm{fa}$ of the Dutch Copyright Act are distributed online and free of cost or other barriers in institutional repositories. Research outputs are distributed six months after their first online publication in the original published version and with proper attribution to the source of the original publication.

You are permitted to download and use the publication for personal purposes. All rights remain with the author(s) and / or copyright owner(s) of this work. Any use of the publication or parts of it other than authorised under article $25 \mathrm{fa}$ of the Dutch Copyright act is prohibited. Wageningen University \& Research and the author(s) of this publication shall not be held responsible or liable for any damages resulting from your (re)use of this publication.

For questions regarding the public availability of this publication please contact openscience.library@wur.nl 


\title{
Prediction of spoilage of tropical shrimp (Penaeus notialis) under dynamic temperature regimes
}

\author{
D. Sylvain Dabadé a,b, Paulin Azokpota a ${ }^{\text {a }}$ M.J. Robert Nout ${ }^{\mathrm{b}}$, D. Joseph Hounhouigan ${ }^{\mathrm{a}}$, \\ Marcel H. Zwietering ${ }^{\mathrm{b}}$, Heidy M.W. den Besten ${ }^{\mathrm{b}, *}$ \\ a Laboratoire de Biochimie Microbienne et de Biotechnologie Alimentaire, University of Abomey-Calavi, 01 B.P. 526 Cotonou, Benin \\ b Laboratory of Food Microbiology, Wageningen University, P.O. Box 17, 6700 AA Wageningen, The Netherlands
}

\section{A R T I C L E I N F O}

\section{Article history:}

Received 11 December 2014

Received in revised form 3 June 2015

Accepted 10 June 2015

Available online 14 June 2015

\section{Keywords:}

Seafood spoilage

Pseudomonas spp.

Carnobacterium maltaromaticum

Shelf-life prediction

Predictive models

\begin{abstract}
A B S T R A C T
The spoilage activity of Pseudomonas psychrophila and Carnobacterium maltaromaticum, two tropical shrimp (Penaeus notialis) spoilage organisms, was assessed in cooked shrimps stored at 0 to $28{ }^{\circ} \mathrm{C}$. Microbiological, chemical and sensory analyses were performed during storage. P. psychrophila had a higher growth rate and showed a higher spoilage activity at temperatures from 0 to $15^{\circ} \mathrm{C}$, while at $28^{\circ} \mathrm{C}, \mathrm{C}$. maltaromaticum had a higher growth rate. The spoilage activity of $P$. psychrophila was found to be higher in cooked shrimp than in fresh shrimp. Observed shelf-life data of shrimps stored at constant temperatures were used to validate a previously developed model that predicts tropical shrimp shelf-life at constant storage temperatures. Models predicting the growth of the spoilage organisms as a function of temperature were constructed. The validation of these models under dynamic storage temperatures simulating temperature fluctuation in the shrimp supply chain showed that they can be used to predict the shelf-life of cooked and fresh tropical shrimps.
\end{abstract}

(c) 2015 Elsevier B.V. All rights reserved.

\section{Introduction}

Microbial spoilage of fishery products may result in high food losses (Gram and Dalgaard, 2002). Shrimps are particularly known as highly perishable products because, unlike other crustaceans (crabs, lobsters), which can be kept alive until processing, shrimps die soon after being caught (Adams and Moss, 2000). The possibility of estimating the residual shelf life at any stage of a food supply chain is of importance to improve food quality management (Bruckner et al., 2013; Raab et al., 2008). To this end, quantitative microbiology can be an important tool and mathematical models can predict the progression of spoilage processes in foods (McMeekin and Ross, 1996). It is known that only a few members of the spoilage microflora, the so-called specific spoilage organisms (SSOs) produce the defects associated with fishery products spoilage (Dalgaard, 1995a; Gram and Dalgaard, 2002). Therefore, identification of SSOs and determination of their spoilage domain and spoilage level are prerequisites to accurately predict shelf life (Dalgaard, 1995b; Koutsoumanis and Nychas, 2000). In a previous study, assessing the spoilage potential of bacteria isolated from fresh shrimps at the sensory rejection times, we found that isolates capable of producing strong off-odor in iced tropical brackish water shrimp (Penaeus notialis) were Pseudomonas spp. and psychrotrophic lactic acid bacteria (LAB)

\footnotetext{
* Corresponding author.

E-mail address: Heidy.denBesten@wur.nl (H.M.W. den Besten).
}

(Dabadé et al., 2015). However, the quantitative ability of the potential spoilage-causing organisms to spoil shrimps i.e. their spoilage activity was not assessed. In the present work, the fastest growing isolates of each group, namely, Pseudomonas psychrophila and Carnobacterium maltaromaticum (LAB), were selected to assess their spoilage activity and to model their kinetics during shrimp shelf-life. Models on Pseudomonas spp. and C. maltaromaticum have been reported in the literature. Examples are models developed by Alfaro et al. (2013), Bruckner et al. (2013), Gospavic et al. (2008), Koutsoumanis (2001), Lebert et al. (1998), and Neumeyer et al. (1997). However, some of these models were developed using media that do not take into account a potential food matrix effect. Moreover, most of the models were developed in a range of temperatures that are not representative for tropical regions. For instance, the predictive model for the growth of $C$. maltaromaticum by Alfaro et al. (2013) is not reliable above $20{ }^{\circ} \mathrm{C}$ according to the authors. Ambient temperatures in tropical areas are however often higher than $25^{\circ} \mathrm{C}$. Therefore, the objectives of the present work were to develop mathematical models for the growth of $P$. psychrophila and C. maltaromaticum in cooked shrimp (P. notialis) from tropical brackish water that are stored at temperatures relevant for the shrimp supply chain, which ranges from 0 to $28^{\circ} \mathrm{C}$. A model describing the growth of Pseudomonas spp. in fresh shrimps as a function of temperature was also developed. Moreover, models were validated under nonisothermal conditions that reflect temperature fluctuation along the supply chain. 


\section{Materials and methods}

\subsection{Inocula preparation}

P. psychrophila and C. maltaromaticum were pre-cultured in $10 \mathrm{ml}$ of Brain Heart Infusion (BHI) broth (OXOID) for 2 days at $25^{\circ} \mathrm{C}$. The cultures were diluted in peptone physiological saline (pps) $(0.85 \% \mathrm{NaCl}$ (SIGMA), $0.1 \%$ peptone (OXOID)) in order to obtain a concentration of about $6 \log \mathrm{CFU} / \mathrm{ml}$.

\subsection{Shrimp sampling preparation and storage}

Shrimps used in the present study were collected from Lake Aheme, one of the most important shrimp fishing areas in Benin (West Africa). The weight of an individual shrimp was approximately $20 \mathrm{~g}$. Immediately after being caught, shrimps were cooled with ice and transferred to the laboratory to arrive within $2 \mathrm{~h}$. In the laboratory, shrimp samples were divided in two batches. One batch was kept fresh whereas the other batch was cooked $\left(100^{\circ} \mathrm{C}, 30 \mathrm{~min}\right)$. Cooked and fresh shrimp samples were aseptically packed in sealed sterile polyethylene bags (Twirl'em sample bags, Labplas Inc, dimensions: $305 \times 178 \mathrm{~mm}$; thickness: $89 \mu \mathrm{m}$ ). Each pack of cooked shrimp (approximately $300 \mathrm{~g}$ shrimp) was inoculated with $3 \mathrm{~mL}$ of prepared P. psychrophila inoculum or C. maltaromaticum inoculum to obtain an initial concentration of about $4 \log \mathrm{CFU} / \mathrm{g}$. Non-inoculated packs of cooked shrimps in which total viable counts were below the detection limit ( $1 \log \mathrm{CFU} / \mathrm{g}$ ) (data not shown) were used as control. Packs of fresh shrimps were inoculated as described for cooked shrimps, but only with P. psychrophila inoculum. Also for fresh shrimp non-inoculated packs were used as control. Shrimps were stored at $0{ }^{\circ} \mathrm{C}, 4^{\circ} \mathrm{C}, 7^{\circ} \mathrm{C}, 15^{\circ} \mathrm{C}$, and $28^{\circ} \mathrm{C}$ as previously described (Dabadé et al., 2015). At appropriate time intervals, shrimp samples were aseptically taken out from the packs for microbiological, chemical and sensory analyses. Three packs of shrimps were used to obtain triplicate analysis per sampling time point.

\subsection{Microbiological analysis}

Whole shrimp (25 g) and $225 \mathrm{~mL}$ of pps were transferred aseptically into a stomacher bag. The mixture was homogenized for $60 \mathrm{~s}$ using a stomacher (Seward Laboratory Stomacher 400, England). From this first decimal dilution in pps, appropriate decimal dilutions were prepared. Pseudomonas species were enumerated on spread plates of Pseudomonas agar base (OXOID) supplemented with cetrimide, fucidin, and cephaloridine (CFC) (OXOID) and the plates were incubated at $25^{\circ} \mathrm{C}$ for $48 \mathrm{~h}$.

C. maltaromaticum was enumerated on Iron Agar supplemented with $0.04 \%$ L-cysteine (SIGMA) and the plates were incubated at $25{ }^{\circ} \mathrm{C}$ for $72 \mathrm{~h}$ as described by Gram et al. (1987).

\subsection{Chemical analysis}

The method recommended by the European Commission (Commission regulation (EC) No 2074/2005) was used to determine total volatile basic nitrogen (TVBN) in cooked and fresh shrimp. Briefly, perchloric acid (SIGMA) shrimp extract was steam-distilled and the volatile base components were determined by titration.

\subsection{Sensory analysis}

The odor and texture of cooked shrimp, and the odor, color and texture of fresh shrimp were evaluated individually by ten panelists experienced in shrimp freshness evaluation. The overall acceptance of the shrimps was assessed using a scale with three categories: $1=$ shrimp with good quality, 2 = shrimp with marginal quality, but still acceptable 3 = spoiled shrimp (Argyri et al., 2010; Dalgaard et al., 1993; Mejlholm et al., 2005). Sensory rejection time was defined as the moment when
$50 \%$ of the panelists evaluated samples to be in category 3 . When the product was rejected with more than $50 \%$ of the panelists on a sampling date, then the rejection time was estimated by interpolation.

\subsection{Statistical analysis}

A Student's two-tailed t-test or one-way ANOVA (IMB SPSS Statistics 19.0) followed by Tukey's test as post-hoc comparison of means was used to compare the means of data (log counts, TVBN, maximum specific growth rate) from different types of shrimps. Significance was set at $P<0.05$.

\subsection{Primary modeling}

The Baranyi model (Baranyi and Roberts, 1994) as described by Den Besten et al. (2006) (Eq. (1)) and the reparameterized Gompertz model (Zwietering et al., 1990) (Eq. (2)) were fitted to the microbial growth data obtained at $0,4,7,15$, and $28^{\circ} \mathrm{C}$ using Excel's solver function and verified with DMFit curve-fitting software v2.1 (http://www.ifr.ac.uk/ safety/DMFit/default.html).

$$
\begin{aligned}
\log _{10}\left(N_{t}\right)= & \log _{10}\left(N_{0}\right)+\frac{\mu_{\max }}{\ln (10)} \cdot A(t)-\frac{1}{\ln (10)} \\
& \cdot \ln \left[1+\frac{\exp \left(\mu_{\max } \cdot A(t)\right)-1}{10^{\left(\log _{10}\left(N_{\max }\right)-\log _{10}\left(N_{0}\right)\right)}}\right]
\end{aligned}
$$

where $A(t)$ is an adjustment function described by Baranyi and Roberts (1994), $t$ is time (h), $N_{t}$ is the number of microorganisms at time $t$ ( CFU $/ \mathrm{g}), N_{0}$ is the number of microorganisms at time zero (CFU/g), $N_{\max }$ is the maximum number of microorganisms (CFU/g), and $\mu_{\max }$ is the maximum specific growth rate (per hour)

$$
\begin{aligned}
\log _{10}\left(N_{t}\right)= & \log _{10}\left(N_{0}\right) \\
& +\left[\log _{10}\left(N_{\max }\right)-\log _{10}\left(N_{0}\right)\right] \\
& \exp \left\{-\exp \left[\frac{\frac{\mu_{\max }}{\ln (10)} \cdot \exp (1)}{\left[\log _{10}\left(N_{\max }\right)-\log _{10}\left(N_{0}\right)\right]}(\lambda-t)+1\right]\right\}
\end{aligned}
$$

where $t$ is time (h), $N_{t}$ is the number of microorganisms at time $t(\mathrm{CFU} / \mathrm{g})$, $N_{0}$ is the number of microorganisms at time zero (CFU/g), $N_{\max }$ is the maximum number of microorganisms (CFU/g), $\mu_{\max }$ is the maximum specific growth rate (per hour), and $\lambda$ is the lag time (h).

\subsection{Secondary modeling}

To model the effect of temperature on microbial growth, two equations were used: the Ratkowsky equation (Eq. (3)) (Ratkowsky et al., 1982) and the Arrhenius equation (Eq. (4)).

$\mu_{\max }=\left[b_{1}\left(T-T_{\min }\right)\right]^{2}$

$\mu_{\max }=b_{2}\left[\exp \left(\frac{-E_{a}}{R \theta}\right)\right]$

where $\mu_{\max }$ is the maximum specific growth rate (per hour), $T$ is the temperature (in degrees Celsius), $\theta$ is the temperature (in degrees Kelvin), $R$ is the gas constant $\left(8.314 \mathrm{~J} \mathrm{~mol}^{-1} \mathrm{~K}^{-1}\right)$, and $b_{i}, T_{\min }$, and $E_{a}$ are the regression coefficients to be estimated. $T_{\min }$ (in degrees Celsius) is the extrapolated temperature at which a microorganism cannot grow anymore. $E_{a}$ (in $\mathrm{J} \mathrm{mol}^{-1}$ ) is the activation energy.

\subsection{Comparison of model}

To assess the performance of the two secondary models used, we compared the root mean square error of the models (RMSE $E_{\text {model }}$ ) (Eq. (5)) as described by Den Besten et al. (2006) after both 
ln-transformation and square-root-transformation of the data. The fitting of the models was performed on the same scale as the data transformation.

RMSE $_{\text {model }}=\sqrt{\frac{\sum_{i=1}^{n}\left(\text { observed }_{i}-\text { fitted }_{i}\right)^{2}}{n-S} .}$

With observed ${ }_{i}$, observed values; fitted ${ }_{i}$, described values; $n$, number of data points; $s$, number of parameters of the model.

\subsection{Validation of model}

Two types of models were validated in this study. First, a model (Eq. (6)) that predicts the shelf-life of fresh tropical shrimp at any constant storage temperature and which was developed in a previous study, (Dabadé et al., 2015).

Shelf-life $($ days $)=4.5 \times 10^{-15} \times \exp \left(\frac{9650}{\theta}\right)$

where $\theta$ is the storage temperature in degrees Kelvin.

The model was validated in this study using observed shelf-life data of shrimps stored at constant temperatures. Second, independent experiments were conducted to validate the models developed in this study, that predict the growth of $P$. psychrophila in cooked shrimps and Pseudomonas spp. in fresh samples as function of temperature. Shrimps were collected and were stored under dynamic temperatures using two scenarios that simulated the temperature fluctuation in the field. During the first scenario, shrimps were stored first at ambient temperature $\left(28^{\circ} \mathrm{C}\right)$ for $6 \mathrm{~h}$, after which the shrimps were stored alternating $12 \mathrm{~h}$ at $10{ }^{\circ} \mathrm{C}$ and $12 \mathrm{~h}$ at $5{ }^{\circ} \mathrm{C}$ (scenario $28 / 10 / 5^{\circ} \mathrm{C}$ ). During the second scenario, caught shrimps were stored alternating $24 \mathrm{~h}$ in ice $\left(0{ }^{\circ} \mathrm{C}\right.$ ) and $24 \mathrm{~h}$ at $7{ }^{\circ} \mathrm{C}$ (scenario $0 / 7^{\circ} \mathrm{C}$ ). The first scenario is based on the most common shrimp collection and transportation system in which after being caught, shrimps are kept up to $6 \mathrm{~h}$ at ambient temperature $\left(28{ }^{\circ} \mathrm{C}\right)$ before their storage in ice using non-isothermal containers. Shrimps are not always properly iced and their temperature may reach $10{ }^{\circ} \mathrm{C}$ at the reception in shrimp plants (Dabadé et al., 2014). The second scenario is based on a new system of shrimp collection and transportation that is being promoted. In this new system, freshly caught shrimp are stored in ice by fishermen as soon as possible and collected shrimps are transported to shrimp plants using isothermal containers. Shrimp temperature should not exceed $7{ }^{\circ} \mathrm{C}$ at any point of the chain in the new system. To predict microbial growth under nonisothermal conditions, a three phase model (Eq. (7)) (Buchanan et al., 1997) taking into account the maximum specific growth rate estimated with the Ratkowsky equation was used. The average of the respective initial and maximum microbial concentrations obtained during the storage experiments at constant temperature was used.

$$
\left.\begin{array}{l}
\log _{10}\left(N_{t}\right)=\log _{10}\left(N_{0}\right), \text { for } t<\lambda \\
\log _{10}\left(N_{t}\right)=\log _{10}\left(N_{0}\right)+\frac{\mu_{\max }}{\ln (10)} \cdot(t-\lambda), \text { for } \lambda<t<t_{\max } \\
\log _{10}\left(N_{t}\right)=\log \left(N_{\max }\right) \text { for } t \geq t_{\max }
\end{array}\right\}
$$

where $t$ is time (h), $N_{t}$ is the number of microorganisms at time $t(\mathrm{CFU} / \mathrm{g}$ ), $N_{0}$ is the number of microorganisms at time zero (CFU/g), $\lambda$ is the lag time $(\mathrm{h}), t_{\max }$ is the time when the maximum number of microorganisms is reached ( $\mathrm{h}), \mu_{\max }$ is the maximum specific growth rate (per hour), and $N_{\text {max }}$ is the maximum number of microorganisms (CFU/g).

It has been shown that the maximum specific growth rate $\left(\mu_{\max }\right)$ is reciprocally proportional to the lag time $(\lambda)$ (Baranyi and Roberts, 1994; Koutsoumanis et al., 2006; McMeekin et al., 1993; Zwietering et al., 1994a). Although the product $\mu_{\max } \times \lambda$ is not always constant (Koseki and Nonaka, 2012), it generally ranges between approximately 0 and 4 (Koutsoumanis et al., 2006; Zwietering et al., 1994a). In the present study, the lag time was estimated assuming that $\mu_{\max } \times \lambda=1$ and $\mu_{\max } \times \lambda=4$. It was also assumed that there is no additional lag time when a temperature shift occurred during the exponential phase and a temperature shift during the lag phase resulted in a new lag time equivalent to the relative part of the remaining lag phase (Zwietering et al., 1994b).

The performance of the developed models was assessed by graphical comparison of predicted and observed values. In addition, the bias (Eq. (8)) and the accuracy (Eq. (9)) factors according to Ross (1996) were calculated to assess the performance of the developed models as follows:

$$
\begin{aligned}
& B_{f}=10\left(\sum \log \left(t_{\text {predicted }} / t_{\text {observed }}\right) / n\right) \\
& A_{f}=10\left(\sum\left|\log \left(t_{\text {predicted }} / t_{\text {observed }}\right)\right| / n\right) .
\end{aligned}
$$

In the case of the validation of the model that predicts the shelf-life of fresh tropical shrimp at constant storage temperatures, $t_{\text {predicted }}$ are the predicted shelf-life values (in days), $t_{\text {observed }}$ are the observed shelf-life values (in days). In the case of the validation of the models that predict the growth of pseudomonads in shrimps under dynamic temperature regimes, $t_{\text {observed }}$ are times (in hours) at which a given pseudomonad level was observed, $t_{\text {predicted }}$ are predicted times (in hours) to reach this same pseudomonad level. In both cases, $n$ is the number of observations. In the case of the validation of the model predicting shelf-life at constant temperature, $B_{f}$ values higher than 1 show that the predicted shelf-life is on average longer than the observed shelf-life. In the case of the validation of the model predicting the growth of pseudomonads, $B_{f}$ values higher than 1 show that the predicted time to reach the concentration of pseudomonads that indicates spoilage is on average longer than the observed time to reach that concentration. $B_{f}=1$ suggests, on average, a perfect agreement between predicted and observed values. The accuracy factor assesses the absolute deviation between the observed values and the predicted values. $A_{f}=1$ shows a perfect agreement between predicted and observed values. The larger the accuracy factor, the less accurate is the average estimate (Ross, 1996).

The performance of the model predicting shrimp shelf-life at constant storage temperature was also evaluated using the acceptable prediction zone method developed by Oscar (2005). The relative errors (REs) for shelf-life were calculated as

$\mathrm{RE}=($ predicted - observed $) /$ predicted.

RE less than zero represents fail-safe predictions and RE above zero represents fail-dangerous predictions (Oscar, 2005). The boundaries of the acceptable prediction zone proposed by Oscar (2005), which were -0.3 (fail-safe) and 0.15 (fail-dangerous), were used.

\section{Results}

\subsection{Microbial growth during shrimp storage}

Of the two primary models used to describe microbial growth as function of time, the root mean square error of the reparameterized Gompertz model was in general lower than the root mean square error of the Baranyi model (data not shown). Therefore, the reparameterized Gompertz model was used in this study to describe microbial growth data. The microbial growth data of the different shrimp products with the fitted reparameterized Gompertz model are shown in Fig. 1. In cooked inoculated shrimps (Fig. 1A and B), the initial microbial concentration (ca. $4 \log \mathrm{CFU} / \mathrm{g}$ ) increased as expected with a higher rate at higher storage temperatures to maximum concentrations of approximately $10 \log \mathrm{CFU} / \mathrm{g}$ at most of the storage temperatures. The 
initial Pseudomonas spp. concentrations were $4.1 \pm 0.2 \log \mathrm{CFU} / \mathrm{g}$ (mean \pm standard deviation) in fresh shrimp inoculated with P. psychrophila (Fig. 1C) and $3.8 \pm 0.2 \mathrm{log} C \mathrm{FU} / \mathrm{g}$ in fresh noninoculated shrimp (Fig. 1D). In fresh shrimps, the inoculated samples had a shorter lag phase than the non-inoculated. While in fresh noninoculated shrimp, the maximum concentration of Pseudomonas spp. reached $9.1 \pm 0.1 \log \mathrm{CFU} / \mathrm{g}$ at low storage temperatures $\left(0{ }^{\circ} \mathrm{C}\right.$ and $4{ }^{\circ} \mathrm{C}$ ), the maximum concentrations were approximately $7.8 \pm$ $0.1 \log \mathrm{CFU} / \mathrm{g}$ at 7 and $15^{\circ} \mathrm{C}$ and $6.9 \pm 0.2 \log \mathrm{CFU} / \mathrm{g}$ at $28^{\circ} \mathrm{C}$. Fresh shrimps inoculated with $P$. psychrophila also showed a maximum concentration of Pseudomonas spp. of $7.1 \pm 0.1 \log \mathrm{CFU} / \mathrm{g}$ at $28^{\circ} \mathrm{C}$. However, the maximum concentration reached $9.3 \pm 0.1 \log \mathrm{CFU} / \mathrm{g}$ at $7{ }^{\circ} \mathrm{C}$ and $8.4 \pm 0.2 \log \mathrm{CFU} / \mathrm{g}$ at $15^{\circ} \mathrm{C}$. High correlation $(\mathrm{r} \geq 0.97)$ was found between the mean concentration of $P$. psychrophila in cooked shrimps and the mean concentration of Pseudomonas spp. in fresh shrimps inoculated with $P$. psychrophila at storage temperatures ranging between $0{ }^{\circ} \mathrm{C}$ and $15{ }^{\circ} \mathrm{C}$. At $28{ }^{\circ} \mathrm{C}$, a lower correlation was found $(\mathrm{r}=0.85)$ (Fig. S1).

In general, a high concentration (8-9 $\log \mathrm{CFU} / \mathrm{g}$ ) of the inoculated bacteria in cooked shrimps was obtained at the sensory rejection times, while the microbial concentration of Pseudomonas spp. in fresh shrimps at the sensory rejection times was lower.

\subsection{Total volatile basic nitrogen production (TVBN) during storage}

Changes in TVBN values of the different shrimp samples are shown in Fig. 2. The initial TVBN value in freshly caught shrimp was $29.2 \pm$ $2 \mathrm{mg} / 100 \mathrm{~g}$. The cooking step lowered significantly the initial TVBN value to an average of $10.9 \pm 1.5 \mathrm{mg} / 100 \mathrm{~g}$ in cooked shrimps. As expected, the TVBN values increased with time and temperature during the storage of the different shrimp samples. The TVBN values of cooked shrimps inoculated with $P$. psychrophila were significantly higher than the TVBN values of cooked shrimps inoculated with $C$. maltaromaticum during storage at temperatures ranging from 0 to $15^{\circ} \mathrm{C}$. At $28^{\circ} \mathrm{C}$ however, no significant difference in the TVBN values was obtained. The TVBN values in fresh shrimps were significantly higher compared to cooked shrimps until the end of storage.

The TVBN values at the sensory rejection times in cooked shrimps ranged between 43 and $54 \mathrm{mg} / 100 \mathrm{~g}$. Higher values were found with fresh shrimps (73-85 mg/100 g).

\subsection{Modeling the maximum growth rate as a function of temperature}

Of the two secondary models used (Eqs. (3) and (4)), the Ratkowsky model (Eq. (3)) had the lower root mean square error of the residuals $\left(R M S E_{\text {model }}\right)$ (data not shown) and fitted better to the maximum specific growth data as shown in Fig. 3 with P. psychrophila in cooked shrimp. The residual plot of both models is also depicted in Fig. S2 for graphical comparison. Therefore, the Ratkowsky equation was used in this study as secondary model, and the estimated parameters are shown in Table 1 . The effect of temperature on the maximum specific growth rate of $P$. psychrophila and $C$. maltaromaticum in cooked shrimps is shown in Fig. 4A. The growth rate of $P$. psychrophila in cooked shrimp was significantly higher than the growth rate of $C$. maltaromaticum in cooked shrimp at temperatures from 0 to $15^{\circ} \mathrm{C}$. At $28{ }^{\circ} \mathrm{C}$, however, the growth rate of $C$. maltaromaticum was significantly higher than the
A

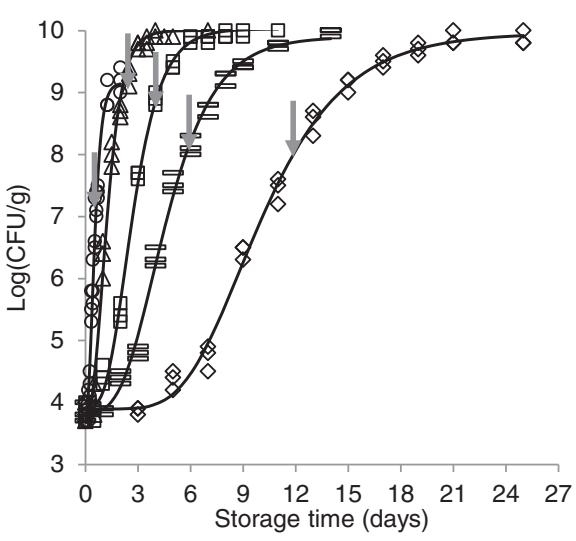

C

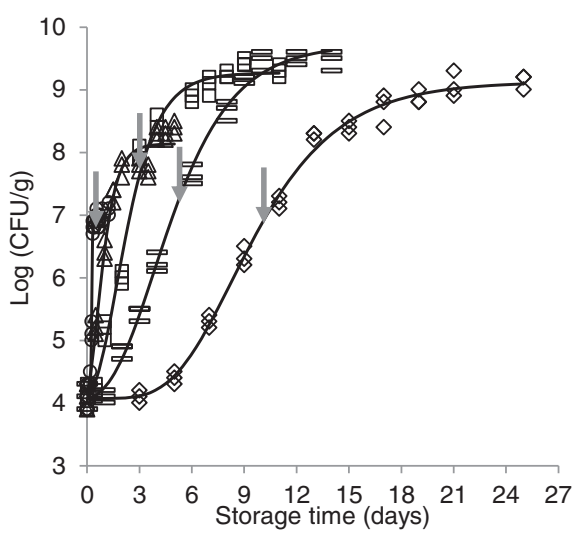

B

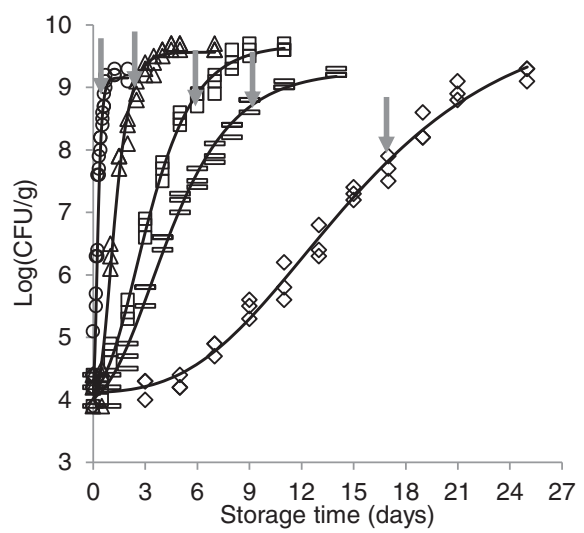

D

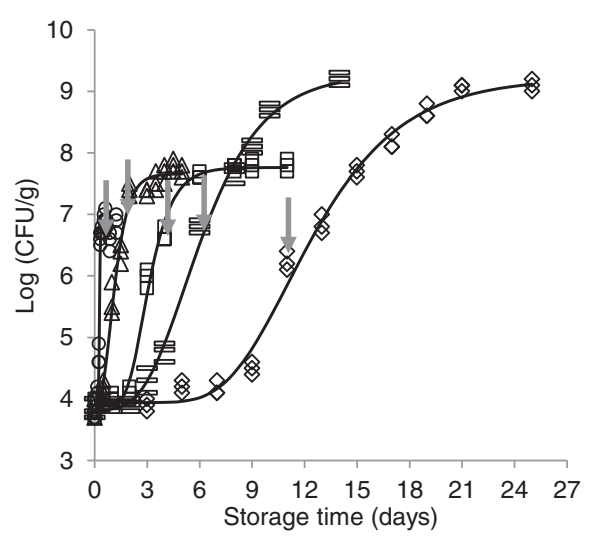

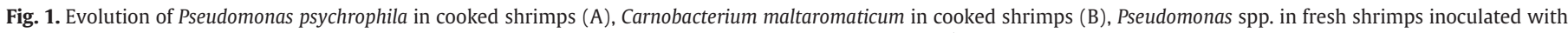

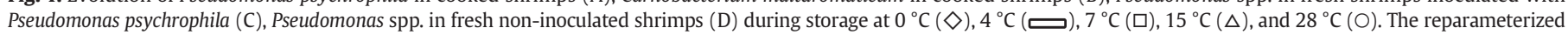
Gompertz model (solid line) was fitted to the growth data. Arrow indicates observed sensory rejection time. 
A

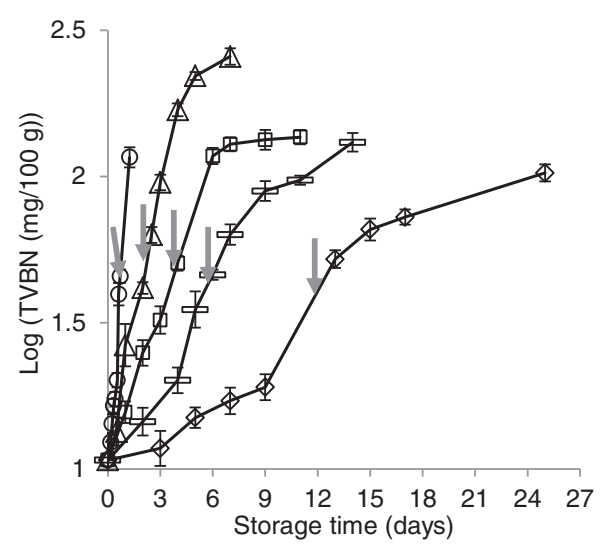

C

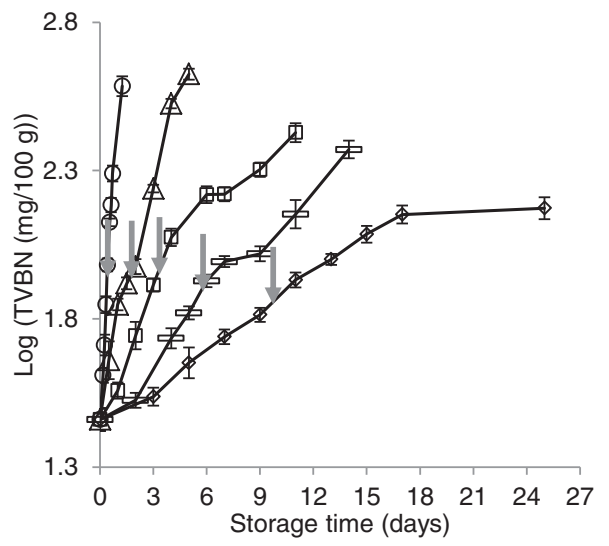

B

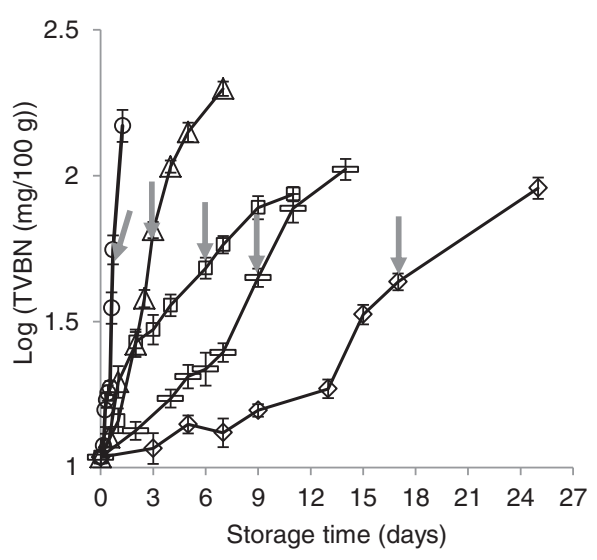

D

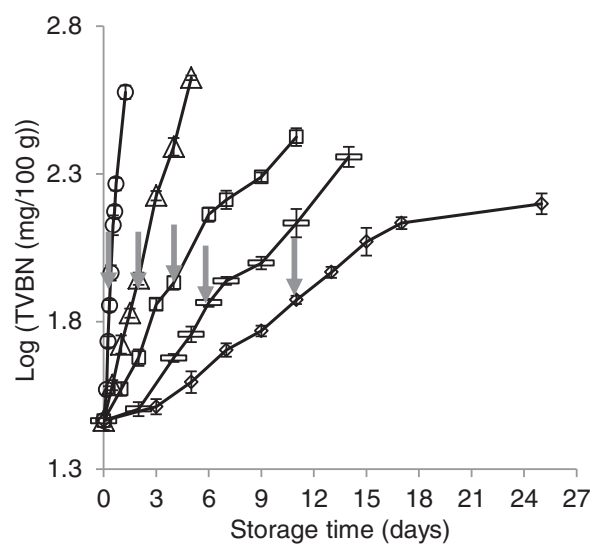

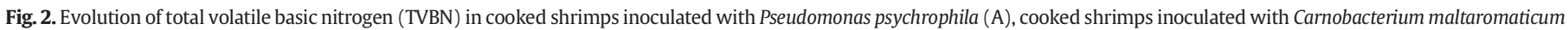

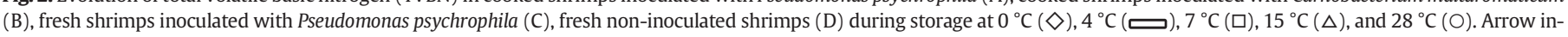
dicates observed sensory rejection time. Bars represent the standard deviation of three independent samples.

growth rate of $P$. psychrophila. In fresh shrimps, the growth rates of Pseudomonas spp. in inoculated and non-inoculated samples were similar (data not shown). The growth rate of P. psychrophila in cooked shrimps was significantly higher than the growth rate of Pseudomonas spp. in fresh non-inoculated shrimps at temperatures ranging from 0 to $15^{\circ} \mathrm{C}$ (Fig. $4 \mathrm{~B}$ ). At $28{ }^{\circ} \mathrm{C}$, the growth rate was high and we could not accurately estimate the maximum growth rate of Pseudomonas spp. in fresh shrimps due to limited data points collected.
A

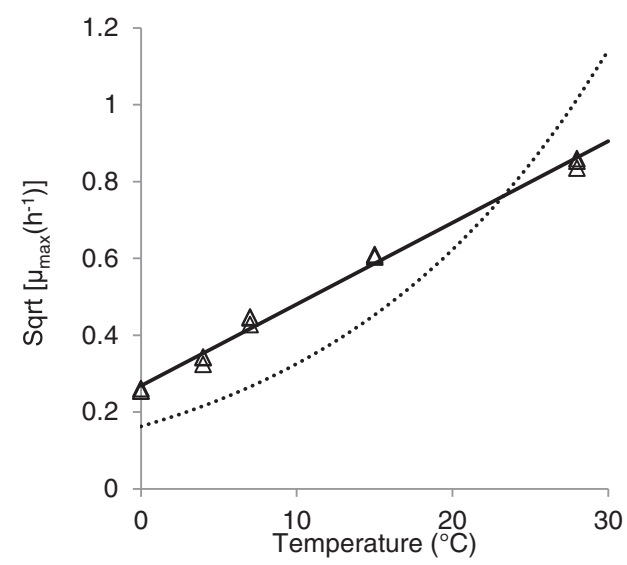

B

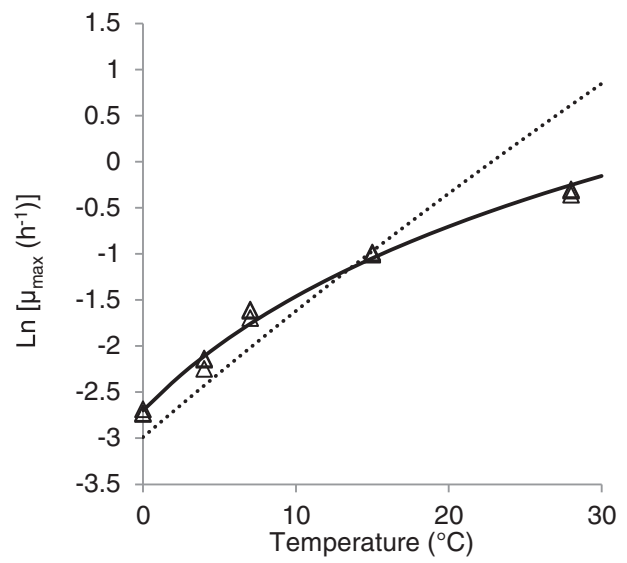

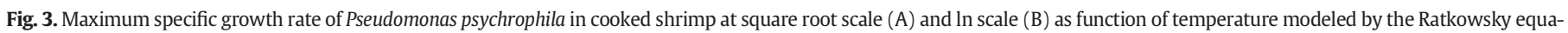
tion (solid line) and Arrhenius equation (dotted line). Both models are represented and fitted on square root scale (A) and ln scale (B). 
Table 1

Parameters (with 95\% C.I.) of the temperature growth rate dependency estimated with the Ratkowsky equation (Eq. (3).

\begin{tabular}{lll}
\hline Microorganisms & $T_{\min }$ & $b_{1}$ \\
\hline $\begin{array}{l}\text { P. psychrophila in cooked shrimp } \\
\text { C. maltaromaticum in cooked }\end{array}$ & $-12.6(-13.4,-11.8)$ & $0.021(0.020,0.022)$ \\
$\quad$ shrimp & $-4.2(-5.3,-3.1)$ & $0.032(0.030,0.034)$ \\
$\begin{array}{c}\text { Pseudomonas spp. in fresh } \\
\text { shrimps inoculated with }\end{array}$ & $-12.1(-13.1,-11.1)$ & $0.019(0.017,0.021)$ \\
$\begin{array}{l}\text { P. psychrophila } \\
\text { Pseudomonas spp. in } \\
\text { non-inoculated shrimps }\end{array}$ & $-12.0(-13.1,-10.9)$ & $0.019(0.017,0.021)$ \\
\hline
\end{tabular}

\subsection{Validation of the model predicting shrimp shelf-life at constant storage} temperatures

A graphical comparison of the predicted shrimp shelf-life values from an earlier study (Eq. (6)) and those experimentally observed at constant temperature in this study with different types of shrimps, is shown in Fig. 5. Relative errors for shrimp shelf-life (days) ( Eq. (10)) plotted against storage temperatures of the different types of shrimps are also shown in Fig. S3. The bias factors and accuracy factors of the model are presented in Table 2 . The $B_{f}$ values ranged between 0.61 and 1.06 and the $A_{f}$, between 1.06 and 1.65 for the types of shrimps used.

\subsection{Model validation and shrimp shelf-life prediction and validation under} non-isothermal conditions

The predicted and observed microbial growth under non-isothermal conditions is depicted in Fig. 6. The bias factors and accuracy factors of the models are shown in Table 3. The models developed based on a low value of the product maximum specific growth rate and lag time $\left(\mu_{\max } \times \lambda=1\right)$ gave better prediction with the scenario involving high storage temperatures (scenario 28/10/5), while with the low temperatures scenario $(0 / 7)$, a high value of the product maximum specific growth rate and lag time $\left(\mu_{\max } \times \lambda=4\right)$ was more appropriate for pseudomonads growth prediction. The developed growth models were used to predict the shelf-life of shrimps at non-isothermal conditions. The shelf-life of cooked shrimps inoculated with $P$. psychrophila was defined as the time at which the microbial concentration is $8.5 \log \mathrm{CFU} / \mathrm{g}$, which was the average concentration of $P$. psychrophila at the sensory rejection time obtained in this study when shrimps were stored at constant temperatures. Fresh shrimp shelf-life was defined as the time at which the concentration of Pseudomonas spp. reaches $6.5 \log \mathrm{CFU} / \mathrm{g}$, which was the average concentration of Pseudomonas spp. in fresh non inoculated shrimps at the sensory rejection time obtained in this study when shrimps were stored at constant temperatures. The predicted shelf-life values based on the models and the observed shelf-life values by sensory analysis are shown in Table 4.

\section{Discussion}

The present study aimed to assess the spoilage activity of P. psychrophila and C. maltaromaticum in tropical shrimp (P. notialis), to develop models that predict the growth of spoilage bacteria in $P$. notialis as a function of temperature and to validate the models.

The ability of $P$. psychrophila and C. maltaromaticum to produce offodor in shrimp has been reported (Dabadé et al., 2015). According to Gram et al. (2002), to identify the most important spoilage microorganisms of a product, it is crucial to assess their quantitative ability to produce spoilage metabolites. The present work shows that $P$. psychrophila produced significantly higher amounts of total volatile basic nitrogen (TVBN) than C. maltaromaticum at storage temperatures varying between $0-15^{\circ} \mathrm{C}$. This is consistent with the sensory analysis that showed a shorter rejection time with cooked shrimps inoculated with P. psychrophila in comparison with cooked shrimp inoculated with C. maltaromaticum between 0 and $15^{\circ} \mathrm{C}$. The chemical and sensory results agreed with the microbiological results since within the same temperature range, the growth rate of $P$. psychrophila was significantly higher than that of $C$. maltaromaticum. Although at $28{ }^{\circ} \mathrm{C}$ the growth rate of $C$. maltaromaticum was significantly higher than that of P. psychrophila, the sensory rejection times of shrimps inoculated with both organisms were comparable. Our microbiological, chemical and sensory results suggest that $P$. psychrophila spoils air-stored tropical shrimp ( $P$. notialis) faster than $C$. maltaromaticum at temperatures ranging from 0 up to $15^{\circ} \mathrm{C}$. Similar results have been reported in meat by Casaburi et al. (2011) and Ercolini et al. (2010) who showed that Pseudomonas fragi had a higher sensory impact on meat stored at $4{ }^{\circ} \mathrm{C}$ than C. maltaromaticum in air or vacuum-packaged. In contrast, Macé et al. (2014) showed that in cooked tropical shrimp (Penaeus vannamei) stored under modified atmosphere packaging at $8^{\circ} \mathrm{C}, \mathrm{C}$. maltaromaticum was the strongest spoiler in comparison with other bacterial species including a member of Pseudomonadales (Psychrobacter sp.). In our study, C. maltaromaticum as well as $P$. psychrophila were inoculated in shrimps of which the endogenous flora was heat inactivated. Thus, it is unlikely that the inoculated microorganisms competed for resources such as nutrients and oxygen with other microorganisms. Also, oxygen was not
A

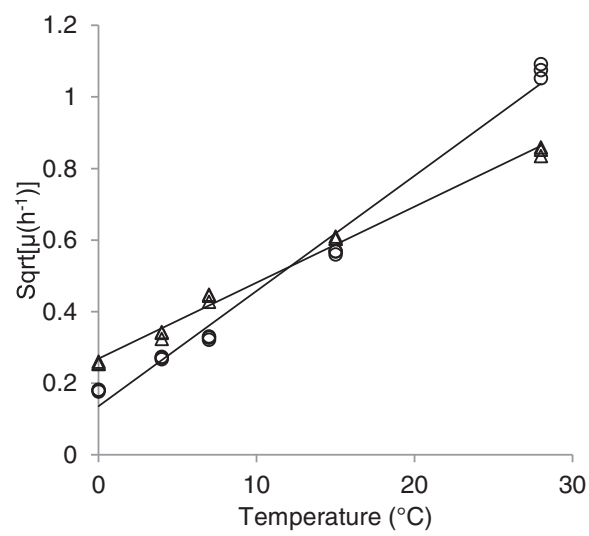

B

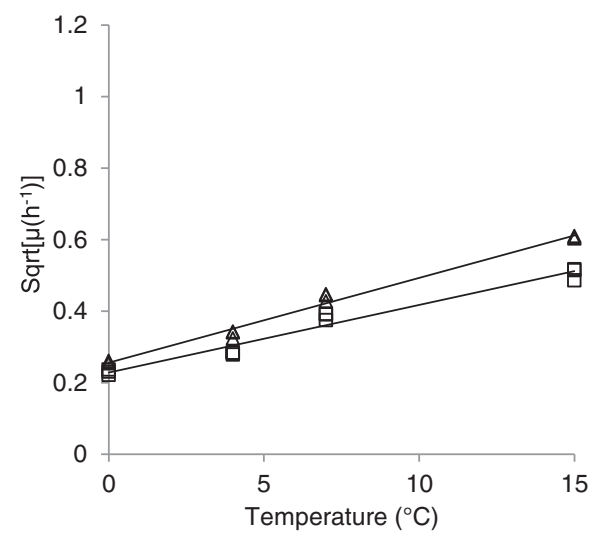

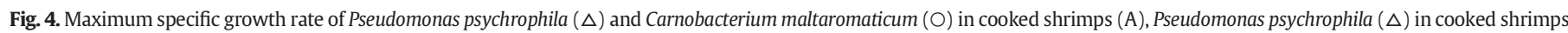
and Pseudomonas spp.( $\square$ ) in fresh non-inoculated shrimps (B) at different temperatures modeled by the Ratkowsky equation (solid line). 


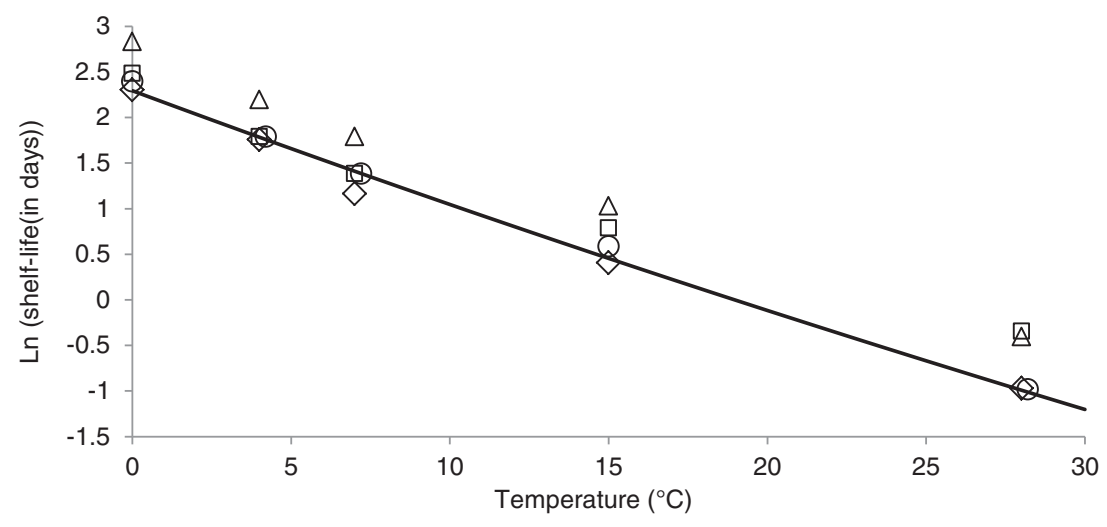

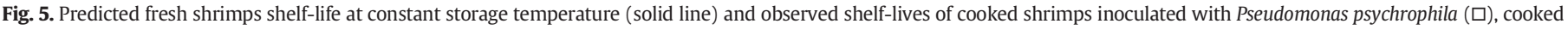
shrimps inoculated with Carnobacterium maltaromaticum $(\Delta)$, fresh shrimps inoculated with Pseudomonas psychrophila $(\diamond)$, fresh non-inoculated shrimps $(\bigcirc)$.

probably a limiting factor since packs of shrimps stored at $28^{\circ} \mathrm{C}$ were opened almost every $2 \mathrm{~h}$ for sampling, and every 24-48 $\mathrm{h}$ at the lower temperatures. Our data on spoilage of tropical shrimp (P. notialis) are in agreement with recent studies on spoilage of cooked cold water shrimp (Pandalus borealis) (Laursen et al., 2006) and cooked tropical shrimp (P. vannamei) (Jaffres et al., 2011; Macé et al., 2014) showing that $C$. maltaromaticum produces volatile compounds such as ammonia (TVBN compound) and other chemical compounds that spoil cooked shrimp. However, whether we should consider $C$. maltaromaticum as a weak or strong shrimp spoiler, it will depend on the types of other spoilage flora associated with the product, which in turn depend on the storage conditions. C. maltaromaticum, which is known to show high resistance to $\mathrm{CO}_{2}$ and to lack of $\mathrm{O}_{2}$ (Alfaro et al., 2013), can outcompete aerobic bacteria and become the strongest spoiler in modifiedatmosphere-packaging or vacuum-packaging, but in air-stored shrimp, its spoilage impact is limited in the presence of more active aerobic spoilers such as Pseudomonas spp.

The microbiological analysis revealed that Pseudomonas spp. were the predominant microorganisms in fresh shrimp at low storage temperatures ( 0 and $4{ }^{\circ} \mathrm{C}$ ) with a maximum concentration reaching $9 \log \mathrm{CFU} / \mathrm{g}$. However, their maximum concentration was 1-$2 \log \mathrm{CFU} / \mathrm{g}$ lower at storage temperatures ranging from 7 to $28^{\circ} \mathrm{C}$. This difference could be explained by an antagonistic or competitive activity of other groups of microorganisms that predominate at high storage temperatures. Several previous studies have reported interaction between spoilage microflora of seafood. For example, it has been documented that siderophore-producing Pseudomonas spp. inhibit the growth of Shewanella putrefasciens, lowering its maximum concentration in fish stored at $0{ }^{\circ} \mathrm{C}$ up to $2 \log \mathrm{CFU} / \mathrm{g}$ (Gram, 1993; Gram et al., 2002; Gram and Melchiorsen, 1996). The cooking effect on physicochemical characteristics of shrimps rendering some nutrients (e.g. amino acids) more easily accessible to the microorganisms may explain why the growth rate of Pseudomonas spp. was lower in fresh shrimps in comparison to P. psychrophila in cooked shrimps. Another reason could

Table 2

Bias factor and accuracy factor of the model predicting fresh shrimp shelf-life at constant storage temperatures.

\begin{tabular}{lll}
\hline Types of shrimps & $\begin{array}{l}\text { Bias factor } \\
\left(B_{f}\right)^{\mathrm{a}}\end{array}$ & $\begin{array}{l}\text { Accuracy factor } \\
\left(A_{f}\right)^{\mathrm{a}}\end{array}$ \\
\hline Cooked shrimp inoculated with P. psychrophila & 0.79 & 1.27 \\
Cooked shrimp inoculated with C. maltaromaticum & 0.61 & 1.65 \\
Fresh shrimp inoculated with $P$. psychrophila & 1.06 & 1.08 \\
Non-inoculated fresh shrimps & 0.95 & 1.06 \\
\hline
\end{tabular}

a $B_{f}$ and $A_{f}$ were calculated based on the comparison between the predicted and observed shelf-life. be the interaction among endogenous flora in fresh shrimps and the reduction in maximum concentration of microorganisms by overgrowing flora which is known as the Jameson effect (Gram et al., 2002; Jameson, 1962; Mellefont et al., 2008). In a previous study, we found that at high storage temperatures, $\mathrm{H}_{2} \mathrm{~S}$-producing bacteria were the dominant group of microorganisms associated with shrimps caught from the same lake (Dabadé et al., 2015). We found similar growth rates of Pseudomonas spp. in fresh shrimps inoculated with P. psychrophila and fresh non-inoculated shrimps (results not shown). This similarity could be explained by the fact that the inoculated P. psychrophila, found to be the fastest growing Pseudomonas spp. spoiling fresh shrimps (Table S1), was previously isolated from a fresh sample and it might be likely to be associated with non-inoculated shrimps in this study. It is known that in a mixed population, the growth rate of the population is similar to that of the fastest growing organism (McMeekin et al., 1993).

The initial total volatile basic nitrogen value (TVBN) found in fresh shrimp (P. notialis) in this study $(29.2 \mathrm{mg} / 100 \mathrm{~g})$ was similar to the one found in a previous study (Dabadé et al., 2015) on the same species of shrimp collected in the same lake ( $30.1 \mathrm{mg} / 100 \mathrm{~g}$ ) and to the value (30 mg/100 g) found in pink shrimp (Parapenaeus longirostris) caught in Spain (López-Caballero et al., 2007). The initial value of TVBN in cooked shrimp was significantly lower than in fresh shrimp probably because some nitrogen compounds evaporated or were released into the cooking water as previously demonstrated (Cambero et al., 1998). The TVBN values at the sensory rejection times (43-54 mg/100 g) of cooked shrimps were significantly lower than those of fresh shrimps $(73-85 \mathrm{mg} / 100 \mathrm{~g})$. This suggests that TVBN standard rejection values of a given seafood product should take into consideration the processing undergone by the product. It would also indicate that compounds in TVBN may differ for cooked or fresh shrimps or that other compounds are involved in rejection.

The conceptual minimal temperature $T_{\min }$ for pseudomonad growth found in this study (Table 1 ) is lower than those previously reported $\left(-8\right.$ to $\left.-5^{\circ} \mathrm{C}\right)$ for the same group of microorganisms (Gospavic et al., 2008; Neumeyer et al., 1997). However, similar value of $T_{\min }$ for pseudomonad growth in fish (Sparus aurata) has been reported by Koutsoumanis (2001). According to this author, strains variability and differences in the structure and the composition of the growth medium (real food versus laboratory medium) are some reasons that could explain the low value of $T_{\min }$ found.

According to Dalgaard (2000), a $B_{f}$ in the range of 0.75-1.25 indicates a successful evaluation of seafood spoilage models. The validation of the model (Eq. (6)) predicting fresh shrimp shelf-life at constant storage temperatures (Table 2 ) shows that the model can be used to successfully predict the shelf-life of fresh shrimps as well as cooked shrimps inoculated with $P$. psychrophila. However, with a $B_{f}$ value of 0.61 , the 

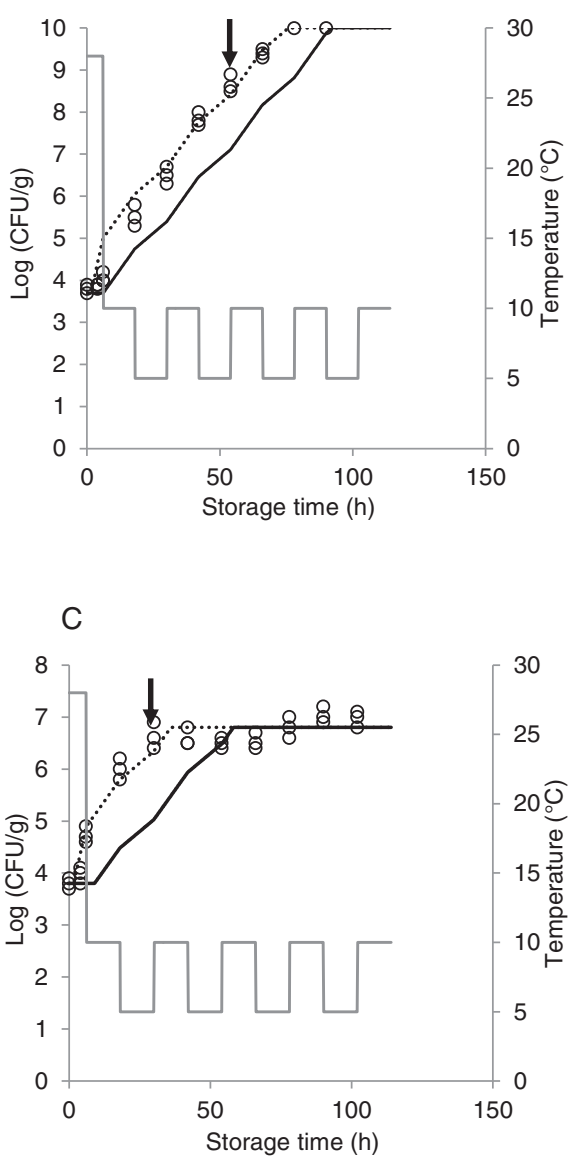

B

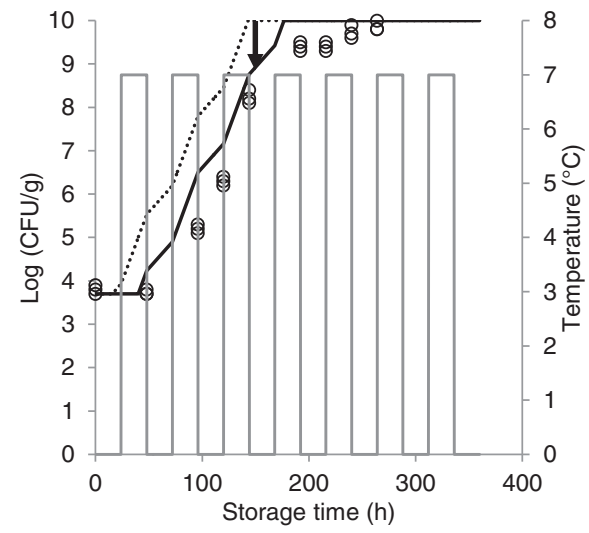

D

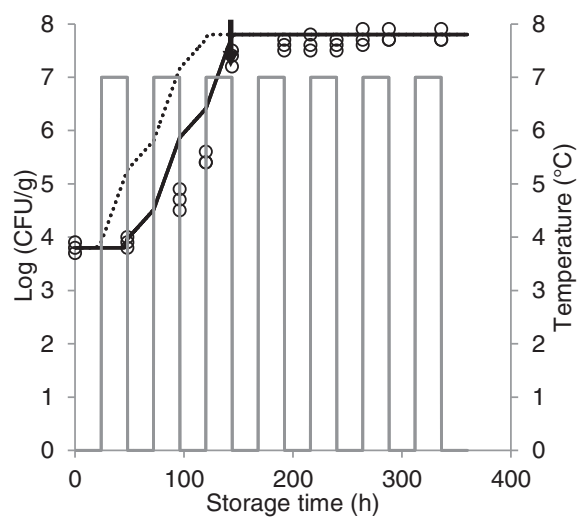

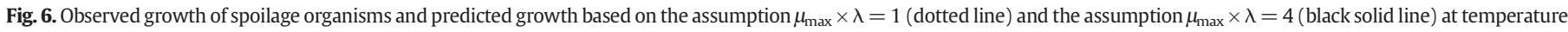

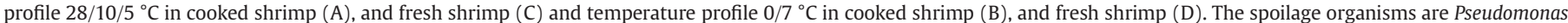

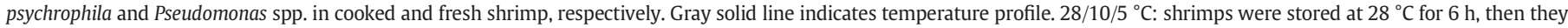

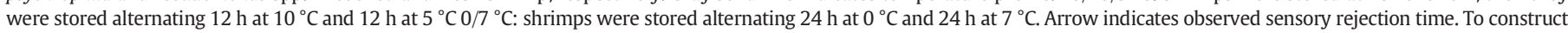

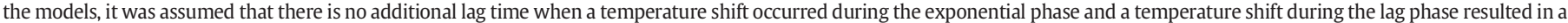
new lag time equivalent to the relative part of the remaining lag phase.

shelf-life of cooked shrimps inoculated with C. maltaromaticum cannot be predicted well by the model. The acceptable prediction zone method (Fig. S3) also confirmed this since all the relative errors for the shelf-life of cooked shrimps inoculated with $C$. maltaromaticum were outside the acceptable prediction zone. Although the model can be used to support shrimp stakeholders' decisions regarding shrimp quality management,

Table 3

Bias factor and accuracy factor of the models predicting the growth of Pseudomonas psychrophila in cooked shrimps and Pseudomonas spp. in fresh shrimps at two temperature profiles.

\begin{tabular}{llll}
\hline & $\begin{array}{l}\text { Temperature } \\
\text { profile }^{\mathrm{a}}\end{array}$ & $\begin{array}{l}\text { Bias factor } \\
\left(B_{f}\right)^{\mathrm{b}}\end{array}$ & $\begin{array}{l}\text { Accuracy factor } \\
\left(A_{f}\right)^{\mathrm{b}}\end{array}$ \\
\hline P. psychrophila in cooked shrimps & $28 / 10 / 5$ & 0.77 & 1.32 \\
& $0 / 7$ & 0.83 & 1.21 \\
Pseudomonas spp. in fresh shrimps & $28 / 10 / 5$ & 0.90 & 1.26 \\
& $0 / 7$ & 0.85 & 1.19 \\
\hline
\end{tabular}

\footnotetext{
a $28 / 10 / 5$ : shrimps were stored at $28^{\circ} \mathrm{C}$ for $6 \mathrm{~h}$, then they were stored alternating $12 \mathrm{~h}$ at $10{ }^{\circ} \mathrm{C}$ and $12 \mathrm{~h}$ at $5{ }^{\circ} \mathrm{C}$ (see Fig. $6 \mathrm{~A}$ or $\mathrm{C}$ ).

0/7: shrimps were stored alternating $24 \mathrm{~h}$ at $0^{\circ} \mathrm{C}$ and $24 \mathrm{~h}$ at $7{ }^{\circ} \mathrm{C}$ (see Fig. $6 \mathrm{~B}$ or $6 \mathrm{D}$ ).

b $B_{f}$ and $A_{f}$ are values of the models developed based on $\mu_{\max } \times \lambda=1$ for profile $28 / 10 / 5$ and $\mu_{\max } \times \lambda=4$ for temperature profile $0 / 7$. They were calculated based on the comparison between the times microbial counts were observed (enumerated) and the times predicted to reach the same concentration as that observed (enumerated).
}

it cannot predict shelf-life under fluctuating temperature, which often occurs in the supply chain. Moreover, the model cannot take into account the effect of the initial microbial concentration on shrimp shelf-life. Fortunately, these shortcomings are taken into consideration in the models predicting the growth of pseudomonads in shrimp under non-isothermal conditions. To construct these models, the uncertainty of the predictions due to the lag phase was simulated with extremes of the initial physiological state of the microorganisms. Similar approach was also used by Bovill et al. (2001). For steps in the exponential phase, often no (large) lag phases are observed as a result of temperature shift (Bovill et al., 2001; Zwietering et al., 1994b), and also in this study, no clear deviations were observed after growth was initiated. The validation of these models show that they can be used to successfully predict shrimp shelf-life under fluctuating temperature since the $B_{f}$ values obtained (Table 3 ) ranged between 0.75 and 1.25 (Dalgaard, 2000). The good agreement found between the predicted and observed shelf-life of shrimp during both temperature profiles (maximum 15\% difference between the predicted and the observed shelf-life, Table 4) confirmed that the shelf-life of shrimp can be estimated from pseudomonads growth data at different storage temperatures, especially at low temperatures where they are dominant microorganisms.

Although the data at $28{ }^{\circ} \mathrm{C}$ could not be fitted since the growth was so fast that not enough data points were available in the exponential phase, the data were used for the validation of the prediction of Pseudomonas counts at $28^{\circ} \mathrm{C}$ (data not shown). The prediction of the 
Table 4

Predicted and observed shelf-life of cooked tropical shrimp (inoculated with Pseudomonas psychrophila) and naturally contaminated tropical shrimp under dynamic temperature storage.

\begin{tabular}{clccc}
\hline & $\begin{array}{l}\text { Temperature } \\
\text { profile }^{\mathrm{a}}\end{array}$ & $\begin{array}{l}\text { Observed } \\
\text { shelf-life } \\
\text { (h) }\end{array}$ & $\begin{array}{l}\text { Predicted } \\
\text { shelf-life } \\
(\mathrm{h})\end{array}$ & $\begin{array}{l}\text { Difference } \\
(\%)\end{array}$ \\
\hline $\begin{array}{l}\text { P. psychrophila in cooked } \\
\text { shrimps }\end{array}$ & $28 / 10 / 5$ & 54 & 55 & -1.9 \\
Pseudomonas spp. in fresh & $0 / 7$ & 152 & 140.5 & +7.6 \\
shrimps & $28 / 10 / 5$ & 30 & 32 & -6.7 \\
\hline
\end{tabular}

a $28 / 10 / 5$ : shrimps were stored at $28^{\circ} \mathrm{C}$ for $6 \mathrm{~h}$, then they were stored alternating $12 \mathrm{~h}$ at $10{ }^{\circ} \mathrm{C}$ and $12 \mathrm{~h}$ at $5{ }^{\circ} \mathrm{C}$ (see Fig. $6 \mathrm{~A}$ or $\mathrm{C}$ ).

0/7: shrimps were stored alternating $24 \mathrm{~h}$ at $0{ }^{\circ} \mathrm{C}$ and $24 \mathrm{~h}$ at $7{ }^{\circ} \mathrm{C}$ (see Fig. $6 \mathrm{~B}$ or D).

$\mathrm{b}$ Difference between observed and predicted shelf-life values.

counts was based on the maximum specific growth rate estimated at $28{ }^{\circ} \mathrm{C}$ by extrapolation in fresh non-inoculated shrimps (Fig. 4B) and using the three phase model (Eq. (7)). With a $B_{f}$ of 1.07 (calculated as described in Eq. (8)), the validation showed that the prediction was successful (Dalgaard, 2000).

Although shrimp shelf-life prediction was based on Pseudomonas counts, TVBN production could also serve as basis for shrimp shelf-life prediction given the high correlation between both parameters. The relationship between $P$. psychrophila concentration and the production of TVBN is shown in Fig. S4.

The observed shelf-life of fresh shrimp stored under temperature profile $1\left(28 / 10 / 5^{\circ} \mathrm{C}\right)$ where temperature abuse occurred in the first part of the chain $\left(28^{\circ} \mathrm{C}, 6 \mathrm{~h}\right)$, was only $30 \mathrm{~h}$ even though after these first $6 \mathrm{~h}$ at $28^{\circ} \mathrm{C}$, shrimps were stored at lower temperatures, namely $10{ }^{\circ} \mathrm{C}$ (for $12 \mathrm{~h}$ ) and $5{ }^{\circ} \mathrm{C}$ (for $12 \mathrm{~h}$ ). This shelf-life was even shorter than the shelf-life of shrimps stored at a higher constant temperature $\left(15^{\circ} \mathrm{C}\right)(43 \mathrm{~h})$ although they contained similar initial microbial concentrations. A similar observation was reported by Bruckner et al. (2012), who found a remarkable shelf-life reduction of fresh pork and poultry due to temperature abuse in the beginning of storage. Our study highlighted the necessity of cooling shrimps as soon as they are caught. Maintaining the cold chain is also of importance. For example, the observed shelf-life of fresh shrimps stored at a constant temperature of $0{ }^{\circ} \mathrm{C}$ was 11 days. Alternating shrimp storage temperature between $0{ }^{\circ} \mathrm{C}$ (for $24 \mathrm{~h}$ ) and $7{ }^{\circ} \mathrm{C}$ (for $24 \mathrm{~h}$ ) (temperature profile 2 ) reduced the observed shelf-life by almost $50 \%$ ( 6 days).

In conclusion, combining microbiological, chemical and sensory analyses, this study demonstrated that overall, the spoilage activity of $P$. psychrophila in tropical shrimp ( $P$. notialis) is higher than that of C. maltaromaticum. The validation of the model previously developed (Eq. (6)) showed that this model can be used as a tool to adequately predict the shelf-life of tropical shrimps during storage at constant temperatures. Models predicting the growth of pseudomonads as a function of temperatures were developed. Their validation showed that they are able to predict the shelf-life of shrimps in satisfactory manner under dynamic storage temperatures based on the time required by spoilage organisms to reach the spoilage level.

\section{Acknowledgments}

The present study was supported by the Netherlands Universities Foundation For International Cooperation, project NPT/BEN/263. The authors are grateful to Mr. Benoît T. Adéké (Fishery Directorate, Benin) for his advice while designing this study. The authors would like to thank laboratory technicians Mr. Romaric Ouetchehou and Mr. Mathias Hounsou for technical assistance.

\section{References}

Adams, M.R., Moss, M.O., 2000. Food Microbiology. 2nd ed. Royal Society of Chemistry, United Kingdom (Chapter 5).
Alfaro, B., Hernández, I., Le Marc, Y., Pin, C., 2013. Modelling the effect of the temperature and carbon dioxide on the growth of spoilage bacteria in packed fish products. Food Control 29, 429-437.

Argyri, A.A., Panagou, E.Z., Tarantilis, P.A., Polysiou, M., Nychas, G.J., 2010. Rapid qualitative and quantitative detection of beef fillets spoilage based on Fourier transform infrared spectroscopy data and artificial neural networks. Sensors Actuators B Chem. $145,146-154$.

Baranyi, J., Roberts, T.A., 1994. A dynamic approach to predicting bacterial growth in food. Int. J. Food Microbiol. 23, 277-294

Bovill, R.A., Bew, J., Baranyi, J., 2001. Measurements and predictions of growth for Listeria monocytogenes and Salmonella during fluctuating temperature: II. Rapidly changing temperatures. Int. J. Food Microbiol. 67, 131-137.

Bruckner, S., Albrecht, A., Petersen, B., Kreyenschmidt, J., 2012. Influence of cold chain interruptions on the shelf life of fresh pork and poultry. Int. J. Food Sci. Technol. 47, 1639-1646.

Bruckner, S., Albrecht, A., Petersen, B., Kreyenschmidt, J., 2013. A predictive shelf-life model as a tool for the improvement of quality management in pork and poultry chains. Food Control 29, 451-460.

Buchanan, R.L., Whiting, R.C., Damert, W.C., 1997. When is simple good enough: a comparison of the Gompertz, Baranyi, and three-phase linear models for fitting bacterial growth curves. Food Microbiol. 14, 313-326.

Cambero, M.I., Jaramillo, C.J., Ordoñez, J.A., Cobos, A., Pereira-Lima, C.I., de Fernando, G.D.G., 1998. Effect of cooking conditions on the flavour compounds and composition of shrimp (Parapenaeus longirostris) broth. Z. Lebensmittelunters. Forsch. A 206, 311-322.

Casaburi, A., Nasi, A., Ferrocino, I., Di Monaco, R., Mauriello, G., Villani, F., Ercolini, D., 2011. Spoilage-related activity of Carnobacterium maltaromaticum strains in air-stored and vacuum-packed meat. Appl. Environ. Microbiol. 77, 7382-7393.

Dabadé, D.S., den Besten, H.M.W., Azokpota, P., Nout, M.J.R., Hounhouigan, D.J., Zwietering, M.H., 2014. Quality perceptions of stakeholders in Beninese exportoriented shrimp chain. J. Food Prot. 77, 1642-1648.

Dabadé, D.S., den Besten, H.M.W., Azokpota, P., Nout, M.R., Hounhouigan, D.J., Zwietering, M.H., 2015. Spoilage evaluation, shelf-life prediction, and potential spoilage organisms of tropical brackish water shrimp (Penaeus notialis) at different storage temperatures. Food Microbiol. 48, 8-16.

Dalgaard, P., Gram, L., Huss, H.H., 1993. Spoilage and shelf-life of cod fillets packed in vacuum or modified atmospheres. Int. J. Food Microbiol. 19, 283-294.

Dalgaard, P., 1995a. Qualitative and quantitative characterization of spoilage bacteria from packed fish. Int. J. Food Microbiol. 26, 319-333.

Dalgaard, P., 1995b. Modelling of microbial activity and prediction of shelf life for packed fresh fish. Int. J. Food Microbiol. 26, 305-317.

Dalgaard, P., 2000. Fresh and lightly preserved seafoods. In: Man, C.M.D., Jones, A.A. (Eds.), Shelf Life Evaluation of Food, 2nd ed. Aspen Publishing Maryland, USA, pp. 110-139.

Den Besten, H.M.W., Mataragas, M., Moezelaar, R., Abee, T., Zwietering, M.H., 2006. Quantification of the effects of salt stress and physiological state on thermotolerance of Bacillus cereus ATCC 10987 and ATCC 14579. Appl. Environ. Microbiol. 72, 5884-5894.

Ercolini, D., Casaburi, A., Nasi, A., Ferrocino, I., Di Monaco, R., Ferranti, P., Mauriello, G., Villani, F., 2010. Different molecular types of Pseudomonas fragi have the same overall behaviour as meat spoilers. Int. J. Food Microbiol. 142, 120-131.

Gospavic, R., Kreyenschmidt, J., Bruckner, S., Popov, V., Haque, N., 2008. Mathematical modelling for predicting the growth of Pseudomonas spp. in poultry under variable temperature conditions. Int. J. Food Microbiol. 127, 290-297.

Gram, L., 1993. Inhibitory effect against pathogenic and spoilage bacteria of Pseudomonas strains isolated from spoiled and fresh fish. Appl. Environ. Microbiol. 59, 2197-2203.

Gram, L., Dalgaard, P., 2002. Fish spoilage bacteria-problems and solutions. Curr. Opin. Biotechnol. 13, 262-266.

Gram, L., Melchiorsen, J., 1996. Interaction between fish spoilage bacteria Pseudomonas sp. and Shewanella putrefaciens in fish extracts and on fish tissue. J. Appl. Bacteriol. 80, 589-595.

Gram, L., Trolle, G., Huss, H.H., 1987. Detection of specific spoilage bacteria from fish stored at low $\left(0{ }^{\circ} \mathrm{C}\right)$ and high $\left(20^{\circ} \mathrm{C}\right)$ temperatures. Int. J. Food Microbiol. 4, 65-72.

Gram, L., Ravn, L., Rasch, M., Bruhn, J.B., Christensen, A.B., Givskov, M., 2002. Food spoilage-interactions between food spoilage bacteria. Int. J. Food Microbiol. 78, 79-97.

Jaffres, E., Lalanne, V., Mace, S., Cornet, J., Cardinal, M., Serot, T., Dousset, X., Joffraud, J.J., 2011. Sensory characteristics of spoilage and volatile compounds associated with bacteria isolated from cooked and peeled tropical shrimps using SPME-GC-MS analysis. Int. J. Food Microbiol. 147, 195-202.

Jameson, J.E., 1962. A discussion of the dynamics of Salmonella enrichment. J. Hyg. 60, 193-207.

Koseki, S., Nonaka, J., 2012. Alternative approach to modeling bacterial lag time, using logistic regression as a function of time, temperature, $\mathrm{pH}$, and sodium chloride concentration. Appl. Environ. Microbiol. 78, 6103-6112.

Koutsoumanis, K., Nychas, G.J.E., 2000. Application of a systematic experimental procedure to develop a microbial model for rapid fish shelf life predictions. Int. J. Food Microbiol. 60, 171-184.

Koutsoumanis, K., 2001. Predictive modeling of the shelf-life of fish under non-isothermal conditions. Appl. Environ. Microbiol. 67, 1821-1829.

Koutsoumanis, K., Stamatiou, A., Skandamis, P., Nychas, G.J., 2006. Development of a microbial model for the combined effect of temperature and $\mathrm{pH}$ on spoilage of ground meat, and validation of the model under dynamic temperature conditions. Appl. Environ. Microbiol. 72, 124-134.

Laursen, B.G., Leisner, J.J., Dalgaard, P., 2006. Carnobacterium species: effect of metabolic activity and interaction with Brochothrix thermosphacta on sensory characteristics of modified atmosphere packed shrimp. J. Agric. Food Chem. 54, 3604-3611. 
Lebert, I., Begot, C., Lebert, A., 1998. Growth of Pseudomonas fluorescens and Pseudomonas fragi in a meat medium as affected by $\mathrm{pH}(5.8-7.0)$, water activity $(0.97-1.00)$ and temperature $\left(7-25^{\circ} \mathrm{C}\right)$. Int. J. Food Microbiol. 39, 53-60.

López-Caballero, M.E., Martínez-Alvarez, O., Gómez-Guillén, M.D.C., Montero, P., 2007. Quality of thawed deepwater pink shrimp (Parapenaeus longirostris) treated with melanosis-inhibiting formulations during chilled storage. Int. J. Food Sci. Technol. 42, 1029-1038.

Macé, S., Cardinal, M., Jaffrès, E., Cornet, J., Lalanne, V., Chevalier, F., Sérot, T., Pilet, M.F. Dousset, X., Joffraud, J.J., 2014. Evaluation of the spoilage potential of bacteria isolated from spoiled cooked whole tropical shrimp (Penaeus vannamei) stored under modified atmosphere packaging. Food Microbiol. 40, 9-17.

McMeekin, T.A., Olley, J.N., Ross, T., Ratkowsky, D.A., 1993. Predictive Microbiology: Theory and Application. Research Studies Press, Taunton, Somerset, England.

McMeekin, T.A., Ross, T., 1996. Shelf-life prediction: status and future possibilities. Int. J. Food Microbiol. 33, 65-83.

Mejlholm, O., Boknaes, N., Dalgaard, P., 2005. Shelf-life and safety aspects of chilled cooked and peeled shrimps (Pandalus borealis) in modified atmosphere packaging. J. Appl. Microbiol. 99, 66-76.

Mellefont, L.A., McMeekin, T.A., Ross, T., 2008. Effect of relative inoculum concentration on Listeria monocytogenes growth in co-culture. Int. J. Food Microbiol. 121, 157-168.
Neumeyer, K., Ross, T., McMeekin, T.A., 1997. Development of a predictive model to describe the effects of temperature and water activity on the growth of spoilage pseudomonads. Int. J. Food Microbiol. 38, 45-54.

Oscar, T.P., 2005. Validation of lag time and growth rate models for Salmonella Typhimurium: acceptable prediction zone method. J. Food Sci. 70, M129-M137.

Raab, V., Bruckner, S., Beierle, E., Kampmann, Y., Petersen, B., Kreyenschmidt, J., 2008. Generic model for the prediction of remaining shelf-life in support of cold chain management in pork and poultry supply chains. J. Chain Netw. Sci. 8, 59-73.

Ratkowsky, D.A., Olley, J., McMeekin, T.A., Ball, A., 1982. Relationship between temperature and growth rate of bacterial cultures. J. Bacteriol. 149, 1-5.

Ross, T., 1996. Indices for performance evaluation of predictive models in food microbiology. J. Appl. Bacteriol. 81, 501-508.

Zwietering, M.H., Jongenburger, I., Rombouts, F.M., Van 't Riet, K., 1990. Modeling of the bacterial growth curve. Appl. Environ. Microbiol. 56, 1875-1881.

Zwietering M.H., Cuppers, H.G.A.M., De Wit, J.C., Van 't Riet, K., 1994a. Evaluation of data transformations and validation of a model for the effect of temperature on bacterial growth. Appl. Environ. Microbiol. 60, 195-203.

Zwietering, M.H., De Wit, J.C., Cuppers, H.G.A.M., Van 't Riet, K., 1994b. Modeling of bacterial growth with shifts in temperature. Appl. Environ. Microbiol. 60, 204-213. 